\title{
Year 3 of an S-STEM Summer Scholarship for a Sophomore Bridge Program
}

\section{Dr. Katie Evans, Louisiana Tech University}

Dr. Katie Evans is the Associate Dean of Strategic Initiatives in the College of Engineering and Science, Academic Director of Mathematics and Statistics and Online Programs, the Entergy LP and L/NOPSI \#3 and \#4 Professor of Mathematics, the Director of the Integrated STEM Education Research Center, and the Director of the Office for Women in Science and Engineering and Louisiana Tech University. Dr. Evans also serves as the Chair of the National Academy of Engineering Grand Challenges Scholars Program Proposal Review Committee. She earned her B.S. in Mathematics from Morehead State University, and her M.S. and Ph.D. in Mathematics at Virginia Tech. After a postdoctoral position in Mechanical Engineering at Oregon State University, she joined Louisiana Tech in 2005. Her current research focuses on STEM education and diversity and inclusion initiatives. Dr. Evans has been awarded over $\$ 5 \mathrm{M}$ as PI or Co-PI on federal, state, and local grants. Additionally, she currently serves as the Workforce Development Lead (senior personnel) on a \$6M National Science Foundation EPSCoR project across three universities.

\section{Mitzi Desselles PhD, Louisiana Tech University}

Dr. Desselles is Associate Professor and Chester Ellis Endowed Professorship in the Department of Psychology and Behavioral Sciences at Louisiana Tech University. She is a member of the graduate faculty in Industrial/Organizational Psychology.

\section{Dr. Marisa K. Orr, Clemson University}

Marisa K. Orr is an Assistant Professor in Engineering and Science Education with a joint appointment in the Department of Mechanical Engineering at Clemson University. Her research interests include student persistence and pathways in engineering, gender equity, diversity, and academic policy. Dr. Orr is a recipient of the NSF CAREER Award for her research entitled, "Empowering Students to be Adaptive Decision-Makers." 


\section{S-STEM Sophomore Bridge Program: Results from "Fast-Forward" Year 3}

The S-STEM Scholarship Program at Louisiana Tech University ("Fast-Forward") welcomed its third cohort in the summer of 2019. The aim of the program is to ease the transition of rising sophomore engineering majors into the more difficult mathematics and engineering courses and help students prepare for the many good things that come with sophomore year, such as closer friendships, leadership opportunities, faculty connections and more relevant classes. The overall objective of the program is to improve engineering retention and, ultimately, to increase the number of STEM graduates entering the workforce.

\section{Program Overview}

The Engineering Fast-Forward Scholarship program provides scholarships and support to engineering majors in the summer between their first and second year, during which they take one engineering and one mathematics course in their major, along with a professional development (PD) course. Scholars also have opportunities to visit regional companies employing engineers and develop closer relationships with faculty. These components of the program, as well as additional student support services and interventions provided through the grant, are described below:

a) Strong cohort experience with increased faculty interaction: The S-STEM Scholars have their own sections of Statics and Calculus III in summer. Students not on the S-STEM scholarship were not permitted to enroll in the S-STEM-dedicated sections of Calculus III or Statics. This also allowed us to schedule the Professional Development course and related activities around their coursework and exam schedules. The course instructors, as well as other faculty from the college, participate in the industry tours to facilitate out-ofclass interaction with faculty.

b) Professional development course: The project team designed a two-credit hour professional development course for the S-STEM Scholars. The 2017 course included curricular components in spatial visualization (Developing Spatial Thinking by Sheryl Sorby [1]) and developing an engineering identity (Studying Engineering: A Road Map to a Rewarding Career, 4th ed, by Raymond Landis [2]). Professional development and engineering identity elements were enhanced in 2018 by the addition of Gallup Clifton StrengthsFinder [3], team-building activities, job search skills, interview skills training, resume design, and professional conduct before, during, and after industry visits. The 2018 project evaluation revealed that students rated these new PD components highly. All have been maintained and, in some cases, expanded for the 2019 program.

c) Dedicated peer tutor: Each cohort has a dedicated tutor for calculus, statics, and spatial visualization (a component of the PD course). Since the program's second year, the tutor has been a former S-STEM scholar. This provides current students with peer support from someone who has been through many of the same program experiences they have. Tutoring is available in the evenings and weekends. 
d) Computer services: We undertook multiple initiatives to provide all first year engineering students with more computer and technical support so they could avoid getting behind in their coursework. On our first-year engineering website, we maintain a complete list of computer, tablet, and smartphone repair businesses in the local area. The project also supports Engineering HelpDesk workers who conduct "Fast-Start" nights each Fall that all first-term engineering freshmen are required to attend. Fast-Start sessions help students navigate through common technical processes before they turn into problems and delay their progress in engineering courses. These include: connecting to the university's secure wireless, locating information about the campus Computing Center and their services, logging in to email, switching from Webmail to Louisiana Tech Gmail, synchronizing email with one's phone, synchronizing calendars, and finding contact information for professors. HelpDesk workers also perform checks of each student's computer to confirm Windows and MS Office installation, to smooth the process for later software installation and coursework. As a note, through a universitywide resource, all first-year engineering majors now have access to virtual desktops with relevant software.

\section{Scholarship Selection}

To date, we have supported 54 students in the Fast-Forward Program. Our to-date target is 60 . The original proposal sought to support 22 students per summer at a level that would cover fulltime tuition and fees, housing, and a meal plan, subject to financial aid eligibility. Due to rising costs of room, board, tuition, and fees at our institution, we have revised the target to 20 students per summer. In the first three years of the program, we have supported 54 students with the median award size of $\$ 6,000$ in Year 1 (average $\$ 5,762$ ) and $\$ 6,500$ in Years 2 and 3 (averaging $\$ 5,945$ and $\$ 6,043$ in Years 2 and 3, respectively). Across the three years the program has been operating, we have had only two students decline the scholarship due to other commitments. Financial aid eligibility has restricted more students participating in the program.

Implementation is going smoothly. There have been no major challenges, only minor ones:

a) Securing on-campus housing and meal plans for scholarship students. Solution: Facilitated communication between our students and specific housing and dining representatives so students could ask questions and understand their options.

b) Landis' Studying Engineering [2] used in the Year 1 professional development course was too basic for rising sophomore engineering majors. Solution: Discontinued Landis material and implemented more relevant professional skills development, e.g. Clifton StrengthsFinder[3], resume writing, mock interviews, job search strategies, research on companies, and professional thank you notes.

c) Recruiting in 2017 resulted in small applicant pools where most students did not meet financial aid eligibility requirements. Solution: advertised more broadly with posters hung around college and held an information session in which previous Fast-Forward scholarship students served as a panel for a Question and Answer session. 


\section{Results}

Project evaluation has included interviews with college faculty and administrators not affiliated with the Fast-Forward Program. College Program Chairs have noted that the S-STEM Scholars are being retained in engineering in a higher proportion than other engineering students who have not been through the program. There is growing enthusiasm for the program through the demonstrated success thus far, which could support the justification for institutionalization postaward.

The research and evaluation teams have continued working closely to coordinate instrument revision and streamline data collection from the S-STEM Scholars. We are tracking course grades, spatial-visualization skills, and student feedback. The evaluation team designed a post survey and a 6-month follow-up survey to assess the program's effectiveness in accomplishing the deliverables, based on student feedback. The survey was deployed at the end of the Summer 2017 and 2018 programs. A similar schedule will be followed for the Summer 2019 cohort of students.

The impact of the program on retention, drop-fail-withdraw (DFW) rates in statics and calculus, and spatial visualization skills are described below. Given the small cohort size each year, statistical tests of change over time by cohort would have very low power. Significance testing of change over time will be conducted using aggregated data after 2020 .

a) Retention: To date, all 35 of the S-STEM Scholars from 2017 and 2018 have been retained in a STEM major. Only three of the 35 students have left engineering. As of June 2019, the cumulative GPA of the Summer 2017 S-STEM Scholars ranges from 2.886 to 3.980 , with an average cumulative GPA of 3.341, while the cumulative GPA of the Summer 2018 S-STEM Scholars ranges from 2.539 to 4.000 , with an average cumulative GPA of 3.240 .

b) Statics drop-fail-withdraw (DFW) rate: S-STEM scholars have experienced a lower DFW in Statics versus comparable figures for the past five years among all engineering students at the University. DFW rate for Statics among S-STEM students in 2017 was $11 \%$ compared to $26 \%$ to $37 \%$ over the past five years. In 2018, the DFW rate for Statics was $24 \%$, which is on the low end for DFW rates typically observed.

c) Calculus drop-fail-withdraw (DFW) rate: The DFW rate for Calculus III among S-STEM students in 2017 was 5.5\%. In 2018, the DFW rate was $24 \%$, which is on the low end of DFW rates typically observed. The DFW rate in Calculus III for the past five years among all engineering students at the University has varied from $25 \%-45 \%$ over the last two years. There is no other 12-week summer section of this multivariable calculus course, so the reference rates may not be directly comparable.

d) Spatial visualization skills: Since 2017, we have assessed pre-to-post changes in spatial visualization skills as a result of exposure to the Sorby curriculum, using the PSVT:R [4]. In 2017, the median improvement was 3 points out of a possible 30 , or $10 \%$. In 2018 , the median improvement pre- to post- was 4 points, or just over $13 \%$. However, since only 
one version of the PSVT:R is available, these changes may be partly attributable to practice effects. In 2018, we introduced the use of equivalent forms of the Revised Minnesota Paper Form Board (RMPFB, [5]) test as a way to more accurately assess the extent to which students improved as a result of the course. The 2018 program data reveals that the median student score on the Form AA of the RMPFB, administered at the beginning of the program, was 47.2, while the median score on Form BB, administered at the end of the program, was 48.8. The median difference was an increase of 1.2 points out of a possible 64 points, or just under a $2 \%$ increase. Based on inspection, it appears that the spatial visualization curriculum is having little effect on student performance on the Minnesota test. One hypothesis regarding the different effects on the two instruments is that they are measuring different aspects of spatial visualization. Use of the Minnesota test will continue in 2019 to collect more data and determine if there is a significant effect.

Finally, our first cohort of S-STEM scholars will be graduating soon. The Fast-Forward program has helped many of them obtain internships and REUs, which they were able to complete and still graduate on-time because they got ahead in their coursework.

\section{Feedback from Students}

Students reported their satisfaction with the interpersonal interaction and cohort development within the program via an evaluation survey. Students reported spending significant time with each other outside of the classes, and they found the peer connections important. They also wanted more purely social events planned with the project personnel.

Responses to the anonymous evaluation survey also indicated that, overall, students enjoyed participating in the research. They did not view it negatively nor did they find it disruptive to classes. They recommended that the research be better integrated into the classes and program, perhaps to more clearly connect the experience to their development as engineers.

Students had a bimodal response to the spatial visualization course content: some students were not interested in the content and found it to be a waste of time, while others found the material challenging. Students also reported that they wanted to see more time in the professional development course focused on the professional side of engineering and integrating these professional skills and reflections with the industry trips.

Program feedback from the eighteen scholarship recipients in 2017 led to significant changes in the professional development course in 2018. We selected industry trips with the most engineering emphasis, increased emphasis on professional identity development, replaced Landis' Studying Engineering [2] content with career development topics guided by CliftonStrengths assessment [3], added a hands-on team-building activity, increased mentoring opportunities between the project faculty and students, and increased integration of the research component of the program by introducing it earlier and in more depth. We retained the entire Developing Spatial Thinking curriculum [1] despite some complaints, because several students improved their skills. The 2018 cohort did not report any problems. 
Feedback from Summer 2018 participants revealed that the above changes were positively received. Overall, the students were more satisfied with the engineering-focused industry visits. They reported that the résumé-building activities and interviewing workshops were beneficial but could be revised to provide more feedback and practice for students. These activities have been re-evaluated to determine an appropriate level of scaffolding, especially for the first draft résumé.

\section{Knowledge Generation Component}

Within the theoretical frameworks of Tinto's Model of Student Departure [6] and Apter's Reversal Theory of motivation [7], we seek to answer the two research questions:

a) To what extent do student STEM-related attitudes and motivations become richer, more psycho-diverse, and more positive as a result of the Summer Bridge experience?

b) What is the linkage between motivational diversity and persistence and success in STEM?

Data collection is on-schedule. The 2020 and 2021 cohorts will yield sufficient data and provide additional statistical power to begin examining our research questions.

The instruments selected by the research team include: the College Persistence Questionnaire (CPQ; dropped 6 items on Motivation to Learn and Scholastic Conscientiousness) [8], the Pittsburgh Engineering Attitudes Scale - Revised (PEAS-R) [9], and the Apter Motivational Style Profile (AMSP) [10]. These surveys were deployed at the beginning and end of the Summer 2017 and 2018 programs. A second post-survey was administered in Spring 2018 for the Summer 2017 program students and in Spring 2019 for the Summer 2018 program students. The same schedule of surveys will be followed for the Summer 2019 cohort of students.

An experiencing-sampling method (ESM, [11-12]) was deployed throughout the 2017 and 2018 programs ( 3 sessions during 15 days over the course of 3 weeks). Each participant was surveyed using a mobile application (Metricwire) installed on students' personal smartphones. The application sent out prompts ("pings") to participants on a randomized schedule within predetermined blocks of time each week. Prompts were scheduled in collaboration with the project team and course teachers to ensure they do not create undue interference with program activities yet capture student motivations and affective reactions in the moment. A similar schedule will be followed for the Summer 2019 cohort of students.

The Purdue Spatial Visualization Test: Rotation (PSVT:R) [4] was selected to assess students' improvement in spatial visualization skills from pre- to post-test. The Revised Minnesota Paper Form Board Test [5] was added in 2018 as a secondary instrument (pre and post) to assess improvements in spatial visualization skills because the Minnesota test offers two equivalent forms. Evaluating change over time in students' spatial visualization using equivalent forms reduces practice effects arising from using the same test in pre and post measures. 


\section{Future Work and Conclusions}

Feedback from the evaluation team suggested no significant adjustments for the next iteration. The plan for Summer 2020 is to continue the program in its present form, employing lessons learned and best approaches from the past three years.

One new area of exploration focuses on why some cohorts have had more positive outcomes than others. One variable that may partially account for some of the differences is whether scholars are employed during the program and/or the regular academic year. Recent research has highlighted the food and housing insecurity and the unmet financial need experienced by many undergraduates, especially those from low-income and under-represented groups (e.g., [13-15]). While the accuracy of the reported figures have been the subject of debate, the issue is relevant for our S-STEM scholar population and warrants investigation. Preliminary data from the thirdyear cohort indicates that at least $60 \%$ of those responding to the follow-up feedback survey were employed during both the summer program and the regular academic year. The team is considering ways to lessen this burden for future cohorts, such as providing more meals and snacks during the program, helping students find on-campus employment that tends to be more supportive of their studies, and providing information about support programs, such as the campus food pantry.

In sum, the Engineering Fast-Forward Scholarship program at Louisiana Tech University continues to provide a multi-faceted set of academic and professional development experiences for low-income, academically talented engineering students.

\section{References}

[1] S. A. Sorby, Developing Spatial Thinking, Boston, MA: Delmar Cengage Learning, 2011.

[2] R. B. Landis, Studying Engineering: A Road Map to a Rewarding Career, 4th ed., Anaheim, CA: Discovery Press, 2013.

[3] M. C. Louis, The Clifton StrengthsFinder and Student Strengths Development, Omaha NE: The Gallup Organization, 2012.

[4] R. B. Guay, Purdue Spatial Visualization Test: Rotations, West Lafayette, IN: Purdue Research Foundation, 1977.

[5] W. H. Quasha and R. Likert, "The revised Minnesota paper form board test," Journal of Educational Psychology, vol. 28, no. 3, pp. 197-204, 1937. https://doi.org/10.1037/h0059880

[6] V. Tinto, Leaving college: Rethinking the causes and cures of student attrition, 2nd ed. Chicago: University of Chicago Press, 1993. 
[7] M. J. Apter, "An introduction to reversal theory," in Motivational styles in everyday life: A guide to reversal theory, Washington, DC, US: American Psychological Association, 2001, pp. 3-35.

[8] W. B. Davidson, H. P. Beck, and M. Milligan, "The college persistence questionnaire: Development and validation of an instrument that predicts student attrition," Journal of College Student Development, vol. 50, no. 4, pp. 373-390, 2009.

[9] J. C. Hilpert, G. Stump, and J. Husman, "Pittsburgh engineering attitudes scale - Revised: Evidence for an improved instrument," Proceedings of the ASEE/IEEE Frontiers in Education Conference, pp. 1-5, 2010.

[10] M. J. Apter, Reversal Theory: the Dynamics of Motivation, Emotion and Personality, Oneworld Publications, Oxford. 2007.

[11] J. M. Hektner, J. A. Schmidt and M. Csikszentmihalyi, Experience sampling method: Measuring the quality of everyday life, Sage, 2007.

[12] M. Csikszentmihalyi and R. Larson, "Validity and reliability of the experience sampling method," in The Expereince of Psychopathology: Investigating Mental Disorders in their Natural Settings, 1992, pp. 43-57.

[13] S. Goldrick-Rab, Paying the price: College costs, financial aid, and the betrayal of the American dream, Chicago, IL: University of Chicago Press, 2016.

[14] S. Goldrick-Rab, J. Richardson, J. Schneider, A. Hernandez, and C. Cady. Still hungry and homeless in college. Madison: Wisconsin HOPE Lab, 2018.

[15] C. J. Nikolaus, B. Ellison, and S. M. Nickols-Richardson. "Are estimates of food insecurity among college students accurate? Comparison of assessment protocols." PloS one 14, no. 4, 2019. doi:10.1371/journal.pone.0215161

\section{Acknowledgements}

This material is supported by NSF DUE \#1564768. Any opinions, findings, conclusions, and recommendations expressed are those of the authors and do not necessarily reflect the views of the National Science Foundation. 